\title{
РЕЗУЛЬТАТИ ГАЛУЗЕВОГО МОНІТОРИНГУ ДІЯЛЬНОСТІ ВИЩИХ НАВЧАЛЬНИХ ЗАКЛАДІВ ТА ЗАКЛАДІВ ПІСЛЯДИПЛОМНОЇ ОСВІТИ МОЗ УКРАЇНИ ЗА ОСНОВНИМИ ПОКАЗНИКАМИ ДІЯЛЬНОСТІ ЗА 2015 КАЛЕНДАРНИЙ РІК
}

\author{
С. В. Григоровська, Ю. С. П’ятницький, О. П. Волосовець, І. Є. Булах, \\ А. Є. Горбань, І. В. Мельник, Ю. І. Фисун \\ Міністерство охорони здоров'я України
}

\section{RESULTS OF UNIVERSITIES AND POST-GRADUATE SCHOOLS OF MINISTRY OF HEALTH OF UKRAINE KEY INDICATORS MONITORING AT 2015 YEAR}

\author{
S. V. Hryhorovska, Yu. S. Pyatnytskyi, O. P. Volosovets, I. Ye. Bulakh, A. Ye. Horban, \\ I. V. Melnyk, Yu. I. Fysun \\ Ministry of Health of Ukraine
}

\begin{abstract}
У 2015 р. був проведений галузевий моніторинг діяльності вищих навчальних закладів та закладів післядипломної освіти МОЗ України за такими основними показниками діяльності, як: навчально-методична робота, наукова діяльність, кадрова політика, міжнародне, державне та галузеве визнання роботи, виховна робота, лікувальна робота, матеріально-технічне забезпечення.

Аналіз показників галузевого моніторингу показує наявність незначного діапазону величини сумарного показника, що відображає існування єдиних підходів до організації навчально-методичної роботи щодо підготовки фахівців для галузі охорони здоров'я, що здійснюється МОЗ України.
\end{abstract}

In sectoral monitoring of universities and post-graduate schools Ministry of Health of Ukraine activity at 2015 year was done according the following key indicators: educational and methodical work, scientific activity, personnel, international, state and sectoral recognition of work, tutorship and students' activity, clinical practice, logistics and supply.

The analysis of the sectoral monitoring indicates the presence of a minor range value of the sum which reflects the existence of common approaches students health care training carried out by $\mathrm{MoH}$ of Ukraine.

Вступ. У поточному році відповідно до наказу Міністерства охорони здоров'я України від 22 листопада 2013 р. № 1000 “Про рейтингове оцінювання діяльності вищих навчальних закладів IV рівня акредитації та закладів післядипломної освіти MO3 України” було здійснено аналіз рейтингових показників діяльності 14 вищих медичних (фармацевтичного) навчальних закладів та 3 закладів післядипломної освіти МОЗ України (далі - ВНЗ MO3 України) за основними показниками діяльності за 2015 календарний рік. Зауважимо, що галузевий рейтинг діяльності ВНЗ МОЗ України за основними напрямами роботи за календарний рік запроваджено Міністерством охорони здоров'я України з 2013 р. [1].
Основна частина. У 2015 р. 3 метою вдосконалення діючого Галузевого рейтингу та приведення його у відповідність до нового Закону України “Про вищу освіту” [2] й інших документів чинної нормативної бази з питань освіти (лист МОЗ України від 07.12.2015 р. № 08.01-47/3865) МОЗ України було ініційовано процедуру збору пропозицій від ВНЗ MO3 України щодо уточнення показників Галузевого рейтингу. Пропозиції щодо уточнення показників були отримані від всіх ВНЗ МОЗ України та скориговані Міністерством охорони здоров'я за участю Центру тестування, Центрального методичного кабінету з вищої медичної освіти МОЗ України, Українського центру наукової медичної інформації та патентно-ліцензійної роботи МОЗ України.

(ㄷ С. В. Григоровська, Ю. С. П’ятницький, О. П. Волосовець та ін. 
Уточнені та скориговані показники за основними напрямками діяльності були затверджені та введені в дію листом МОЗ України від 14.01.2016 р. № 08.01-47/647.

Збір та обробку даних (показників та матеріалів, що подаються разом із показниками), поданих від ВНЗ МОЗ України за 2015 календарний рік, проведено Центром тестування.

Нижче наведені показники рейтингової діяльності ВНЗ у вигляді таблиць. У таблиці 1 подана інформація щодо позиціонування ВНЗ за результатами рейтингового оцінювання діяльності ВН3 за розділами. У таблицях 2-9 наведені дані фактичних розрахунків щодо рейтингової оцінки ВНЗ МОЗ України за показниками з усіх розділів.

Аналіз показників галузевого моніторингу показує наявність незначного діапазону величини сумарного показника, що відображає існування єдиних підходів до організації навчальнометодичної роботи щодо підготовки фахівців для галузі охорони здоров’я, що здійснюється МО3 України.

За результатами проведеної оцінки виокремлено групу кращих ВНЗ:

- Державний вищий навчальний заклад “Тернопільський державний медичний університет імені I. Я. Горбачевського Міністерства охорони здоров’ я України",

- Вищий державний навчальний заклад України “Буковинський державний медичний університет”,

- Національна медична академія післядипломної освіти імені П. Л. Шупика,

- Львівський національний медичний університет імені Данила Галицького.

Разом $з$ тим галузевий моніторинг дозволив визначити сильні та слабкі сторони діяльності кожного ВНЗ, що дає можливість скоригувати перспективний план розвитку навчального закладу для забезпечення належної якості підготовки фахівців [3].

Так, аналіз результатів галузевого моніторингу діяльності ВНЗ за розділами свідчить про необхідність покращення наступних основних показників.

З розділу “Навчально-методична робота”:

- активізації видання навчальних підручників та посібників у ДНМУ, ЛДМУ та ХМАПО;
- поліпшення підготовки студентів/інтернів до складання ліцензійних іспитів “Крок” в ОНМУ, ХНМУ, НМАПО, ХМАПО;

- активного залучення студентів та інших суб’єктів навчання закладу до участі у студентських міжнародних та державних предметних олімпіадах, міжвузівських наукових конференціях студентів та молодих вчених у ДНМУ, ЛДМУ, НМУ, НМАПО та ХНМУ.

3 розділу “Наукова діяльність”:

- активізації роботи щодо отримання патентів: ДНМУ, ЛДМУ, ЛНМУ;

- активізації здобуття ПВС навчальних закладів наукових ступенів кандидата та доктора наук у НМУ, ОНМУ, ДНМУ та ЛДМУ;

- підвищення індексу Хірша у ВНМУ, ЗДМУ, ЛДМУ, ЛДМУ, ТДМУ, УМСА, ЗМАПО і ХМАПО.

3 розділу “Кадрова політика”:

- збільшення кількості професорів, які працюють у ВНЗ, у ВНМУ, ІФНМУ, ЛНМУ та ОНМУ;

- збільшення кількості доцентів, які працюють у ВНЗ, у ДНМУ та ЛДМУ;

- збільшення питомої ваги кандидатів та докторів наук допенсійного віку у ВНМУ, ДМА, ДНМУ та ОНМУ;

- зменшення питомої ваги ПВС без наукового ступеня серед осіб ПВС, які працюють у ВНЗ більше 5-ти років у ВНМУ, ІФНМУ, ЛНМУ та НМУ.

3 розділу “Міжнародне, державне та галузеве визнання роботи":

- активізувати роботу щодо участі ВНЗ у міжнародних грантових програмах та співпраці з іноземними закладами-партнерами у ДНМУ, ЛДМУ, ЗМАПО та ХМАПО.

3 розділу “Виховна робота”:

- залучати студентів/інтернів до участі у спортивних змаганнях (Олімпійських іграх, чемпіонатах світу, Європи, Всесвітніх універсіадах, чемпіонатах України, Універсіадах України, студентських олімпіадах) у ДМА, ХНМУ, ЛДМУ.

3 розділу “Лікувальна робота":

- активізувати видання методичних рекомендацій та інформаційних листів з грифом Українського центру наукової медичної інформації та патентноліцензійної роботи МОЗ України у ВНМУ, ДНМУ, ЛДМУ, ЛНМУ, ОНМУ;

- збільшення кількості нововведень з лікувальнодіагностичної та профілактичної роботи у ДНМУ, лДМУ, ОНМУ та ХНМУ. 


\begin{tabular}{|c|c|c|c|c|c|c|c|c|c|c|c|c|c|c|c|c|c|}
\hline 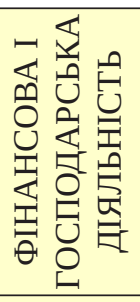 & 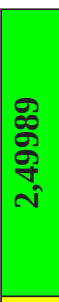 & 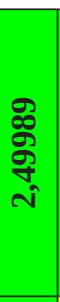 & 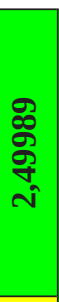 & 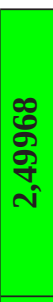 & 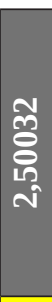 & 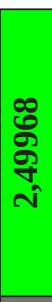 & 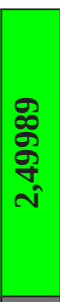 & $\begin{array}{l}\text { fे } \\
\text { वे } \\
\text { ণ }\end{array}$ & 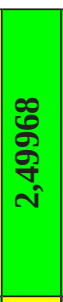 & 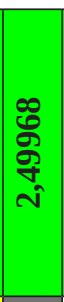 & 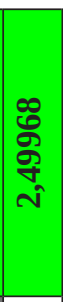 & 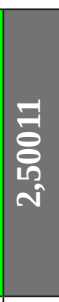 & $\begin{array}{l}\text { 릉 } \\
\text { 소 } \\
\text { 오 }\end{array}$ & 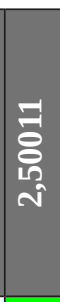 & 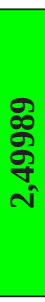 & $\begin{array}{l}\mathscr{8} \\
\mathscr{2} \\
\stackrel{2}{+} \\
\stackrel{\sim}{*}\end{array}$ & 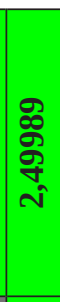 \\
\hline 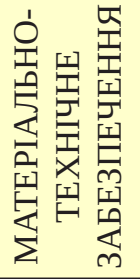 & 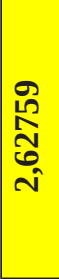 & 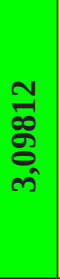 & $\begin{array}{l}\overline{\vec{\Xi}} \\
\grave{\Xi} \\
\dot{m}\end{array}$ & $\begin{array}{l}\frac{a}{\hat{N}} \\
\hat{8} \\
\text { ले }\end{array}$ & 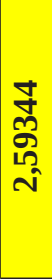 & 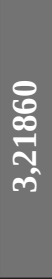 & $\begin{array}{l}\text { yे } \\
\text { ํㅜ } \\
\text { m } \\
\text { m. }\end{array}$ & 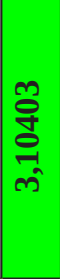 & 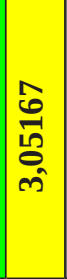 & 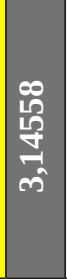 & 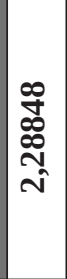 & 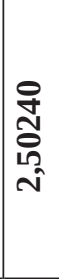 & 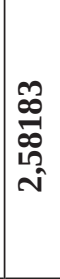 & $\begin{array}{l}\text { yे } \\
\text { oे } \\
\text { ले } \\
\text { ले }\end{array}$ & 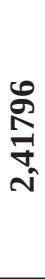 & $\begin{array}{l}\hat{A} \\
\stackrel{-}{A} \\
m\end{array}$ & 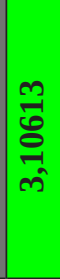 \\
\hline 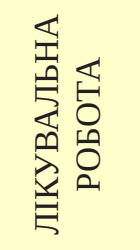 & $\begin{array}{c}\infty \\
\infty \\
0 \\
0 \\
0 \\
\text { ले }\end{array}$ & 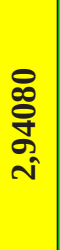 & $\begin{array}{l}\text { हे } \\
\text { సे } \\
\text { ले } \\
\text { ले }\end{array}$ & 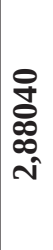 & 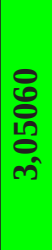 & 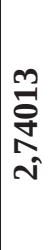 & 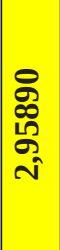 & 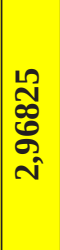 & 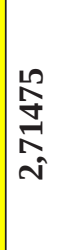 & $\begin{array}{l}\varnothing \\
\frac{\partial}{g} \\
\frac{\partial}{\vec{m}} \\
\text { ले }\end{array}$ & 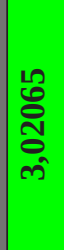 & $\begin{array}{l}\frac{12}{2} \\
\frac{2}{2} \\
\text { ल) }\end{array}$ & 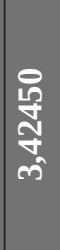 & $\begin{array}{l}0 \\
\text { ஜू. } \\
\text { ల్ } \\
\text { ले }\end{array}$ & $\begin{array}{l}\text { న̂ } \\
\text { ని } \\
\widehat{S} \\
\text { ה }\end{array}$ & 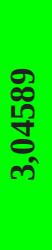 & 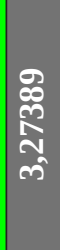 \\
\hline 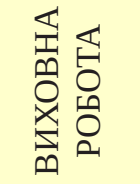 & 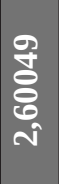 & $\begin{array}{l}\text { 클 } \\
\text { 응 } \\
\text { iv }\end{array}$ & 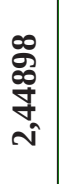 & 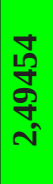 & 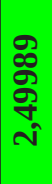 & 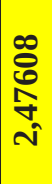 & 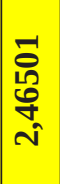 & 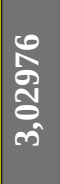 & 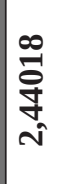 & 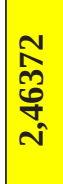 & $\begin{array}{l}0 \\
\text { సे } \\
\text { రे } \\
\text { N }\end{array}$ & 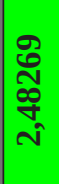 & 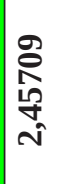 & \begin{tabular}{l}
$\infty$ \\
in \\
in \\
of \\
\multirow{2}{*}{}
\end{tabular} & 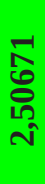 & 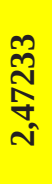 & 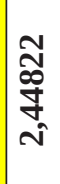 \\
\hline
\end{tabular}

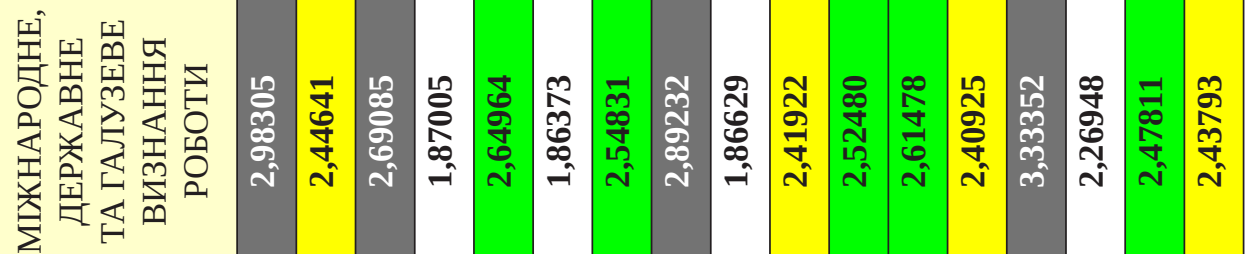

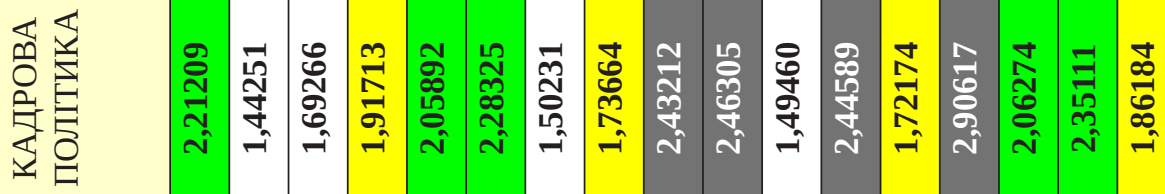

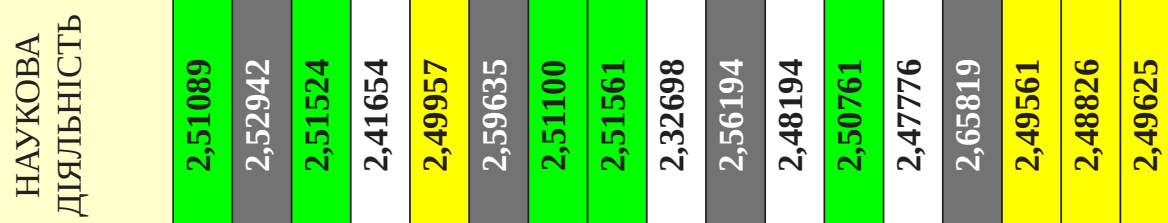

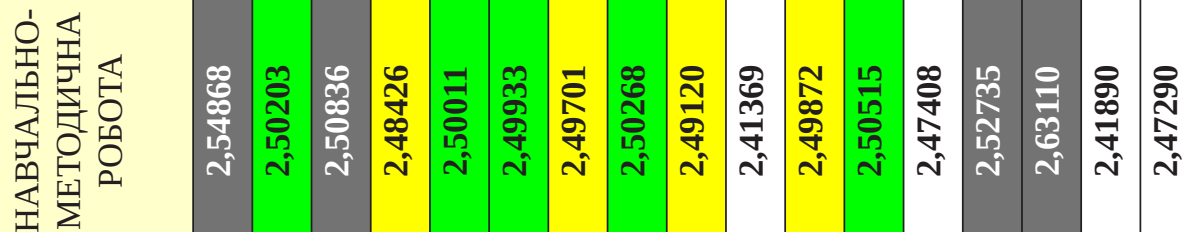

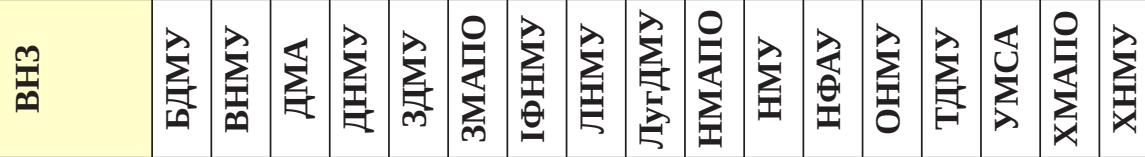




\begin{tabular}{|c|c|c|c|c|c|c|c|c|c|c|c|c|c|c|c|}
\hline 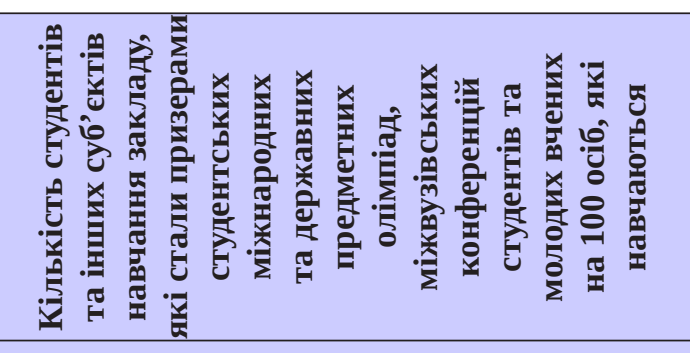 & $\begin{array}{l}\stackrel{ \pm}{m} \\
\stackrel{2}{*}\end{array}$ & $\mid$\begin{tabular}{l}
$\widetilde{\sigma}$ \\
\hdashline \\
$f$
\end{tabular} & $\begin{array}{c}8 \\
\hat{m} \\
m\end{array}$ & & 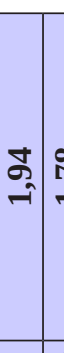 & & & & $\overbrace{-}$ & क् & & 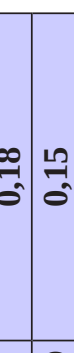 & ठ̊. & $\Xi_{0}$ & \& \\
\hline$\stackrel{n}{\underline{I}}$ & 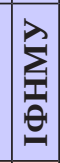 & 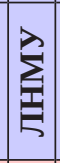 & 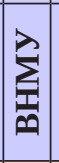 & $\sum_{10}^{\lambda}$ & $\sum_{0}^{2}$ & & & & $\sum_{m}^{\lambda}$ & $\sum_{0}^{\lambda}$ & & $\begin{array}{l}\frac{\lambda}{x} \\
\sum_{x}\end{array}$ & 怘 & & \\
\hline 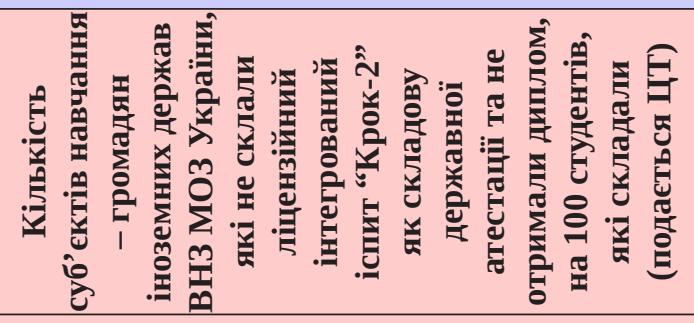 & $\begin{array}{l}8 \\
0\end{array}$ & 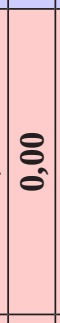 & $\begin{array}{l}0 \\
-1\end{array}$ & $\underset{\sigma}{\sigma}$ & 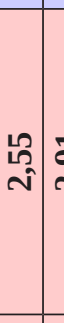 & & & & $\mid \begin{array}{l}1 \\
\hat{\theta} \\
0 \\
0\end{array}$ & $\mid \begin{array}{c}\tilde{m} \\
\tilde{m} \\
\tilde{n}\end{array}$ & & & & & \\
\hline$\stackrel{M}{M}$ & $\sum_{\substack{n \\
\mid \hat{n}}}^{\lambda}$ & 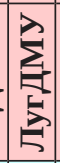 & $\frac{\hat{\theta}}{\hat{\theta}}$ & 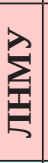 & $\sum_{\infty}^{\lambda}$ & $\sum_{-1}^{\lambda}$ & & & $\sum_{i}^{\lambda}$ & 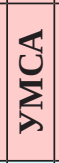 & & 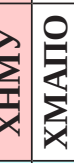 & 递 & & 总 \\
\hline 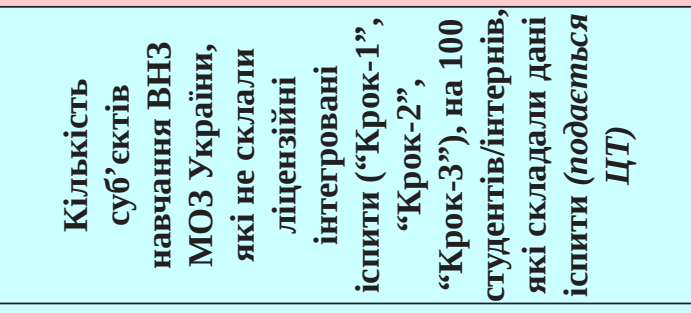 & $\begin{array}{l}1 \\
0 \\
0 \\
0\end{array}$ & $\mid \begin{array}{l}0 \\
0 \\
-1\end{array}$ & $\stackrel{\hat{m}}{-}$ & $\overrightarrow{\widehat{v}}$ & 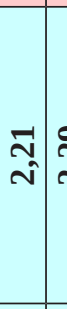 & & & 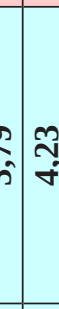 & $\begin{array}{l}\eta \\
⿱ \\
+\end{array}$ & 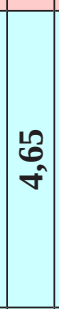 & & 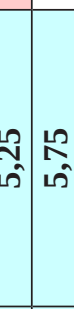 & $\mid \begin{array}{c}\mathscr{8} \\
\mathbb{0} \\
0 \\
0\end{array}$ & 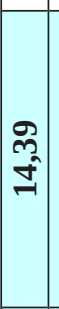 & $\begin{array}{l}\hat{\sigma} \\
\text { เी }\end{array}$ \\
\hline$\stackrel{M}{M}$ & 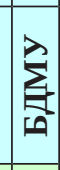 & $\sum^{\lambda}$ & $\sum_{\text {ले }}^{\vec{\lambda}}$ & 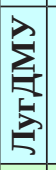 & $\mathbb{\Sigma}$ & 宅 & & 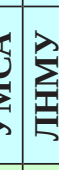 & $\sum^{\lambda}$ & 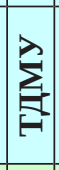 & & $\frac{\lambda}{0}$ & 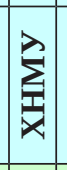 & & 递 \\
\hline 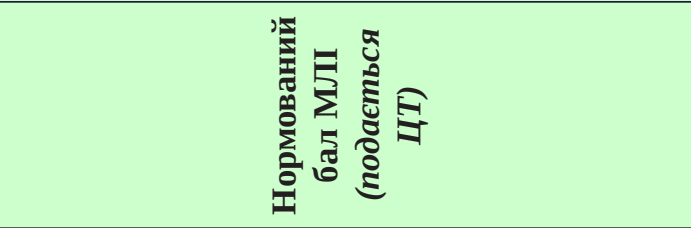 & 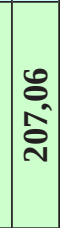 & 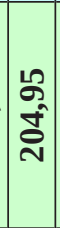 & 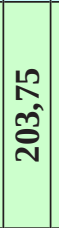 & 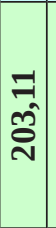 & 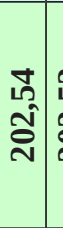 & & & & 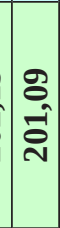 & $\mid \begin{array}{l}\tilde{N} \\
\Omega_{\Omega}^{2} \\
\Omega\end{array}$ & & 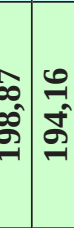 & $\left|\begin{array}{l}0 \\
2 \\
\sigma \\
\sigma\end{array}\right|$ & 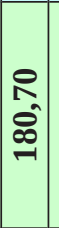 & $\begin{array}{l}\text { ले } \\
\text { స్ } \\
-1\end{array}$ \\
\hline$\stackrel{m}{M}$ & 胹 & 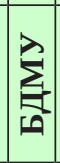 & $\frac{\lambda}{\mathrm{i}}$ & $\sum_{k}^{\mathbb{Z}}$ & $\sum_{1}^{\lambda}$ & & & 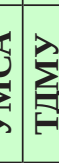 & 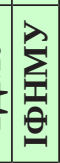 & $\sum_{|=|}^{\lambda}$ & & 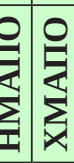 & 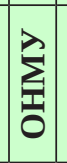 & 离 & $\sum^{\lambda}$ \\
\hline 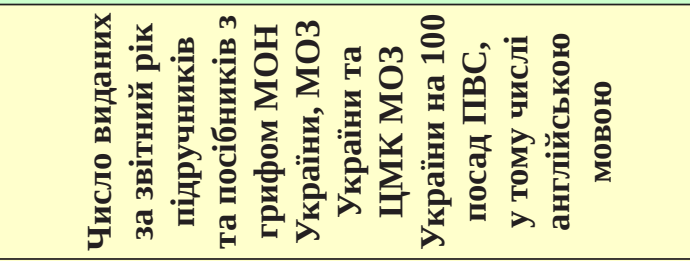 & $\mid \begin{array}{l}\mathfrak{N} \\
\mathfrak{Z} \\
\mathfrak{Z}\end{array}$ & $\mid \begin{array}{l}\tilde{n}^{\prime} \\
\boldsymbol{n}^{2}\end{array}$ & 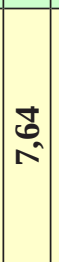 & బิน & $\mid$ & & & 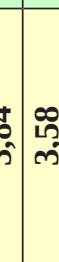 & ले & 命 & $\stackrel{0}{=}$ & 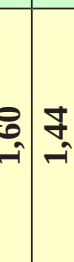 & $\stackrel{m}{=}$ & $\mid \begin{array}{c}\infty \\
\infty \\
0^{\prime}\end{array}$ & $\begin{array}{l}10 \\
0 \\
0 \\
0\end{array}$ \\
\hline 竞 & $\sum_{\lambda}^{\mathbb{S}}$ & 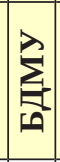 & $\sum_{i=1}^{\lambda}$ & & $\sum_{1}^{\lambda}$ & & & $\frac{2}{\theta}$ & 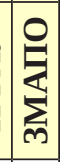 & $\underset{m}{\stackrel{\lambda}{m}}$ & 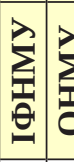 & 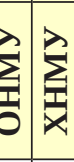 & 窟 & 离 & 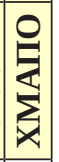 \\
\hline $4 \mathrm{~cm}$ & -1 & & n & & 4 & & & $\sigma$ & 의 & $=$ & & $= \pm$ & 늑 & $\mathscr{- 1}$ & \\
\hline
\end{tabular}




\begin{tabular}{|c|c|c|c|c|c|c|c|c|c|c|c|c|c|c|c|c|c|}
\hline 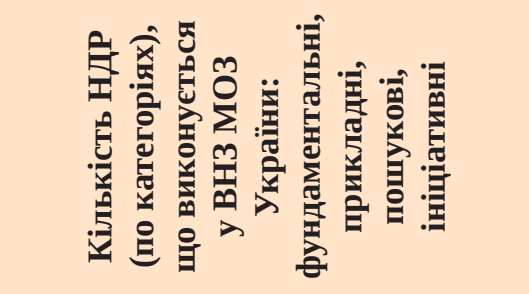 & 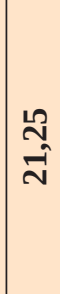 & $\begin{array}{l}\hat{f} \\
\hat{g}\end{array}$ & $\left|\begin{array}{c}-1 \\
\hat{0} \\
\hat{-1}\end{array}\right|$ & $\left|\begin{array}{c}\tilde{\sigma} \\
\hat{\sigma} \\
\ddots\end{array}\right|$ & $\mid \begin{array}{l}\mathbf{L} \\
\hat{n} \\
\end{array}$ & $\begin{array}{l}\tilde{M} \\
\mathcal{U}\end{array}$ & $\begin{array}{l}\mathcal{A} \\
\mathcal{U}\end{array}$ & $\begin{array}{c}\overrightarrow{0} \\
= \\
=\end{array}$ & $\mid$\begin{tabular}{l}
$\infty$ \\
$\infty$ \\
0 \\
\hdashline
\end{tabular} & 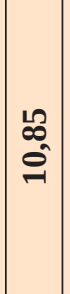 & $\begin{array}{l}L \\
\infty \\
\sigma \\
\sigma\end{array}$ & $\begin{array}{l}\tilde{N} \\
\text { के }\end{array}$ & $\begin{array}{l}\text { N్ } \\
\text { N }\end{array}$ & $\begin{array}{l}2 \\
\qquad \\
6 \\
0\end{array}$ & $\begin{array}{l}0 \\
0 \\
0\end{array}$ & $\begin{array}{l}10 \\
0 \\
-1\end{array}$ & 로 \\
\hline$\stackrel{m}{1}$ & 远 & 齐 & $\sum_{-2}^{\lambda}$ & $\mid \begin{array}{l}\hat{\hat{\theta}} \\
\frac{\hat{T}}{\mathbf{T}}\end{array}$ & 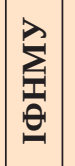 & 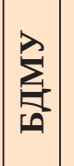 & $\sum_{\lambda}^{\mathbb{J}}$ & $\sum_{\Xi}^{\bigotimes}$ & $\sum_{\bar{m}}^{\lambda}$ & 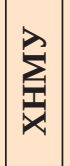 & 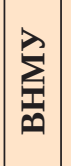 & 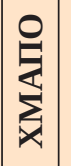 & $\sum_{i}^{\lambda}$ & $\sum_{\substack{1 \\
0}}^{\lambda}$ & $\sum_{i=1}^{\lambda}$ & $\sum_{\text {徥 }}^{0}$ & $\sum^{\lambda}$ \\
\hline 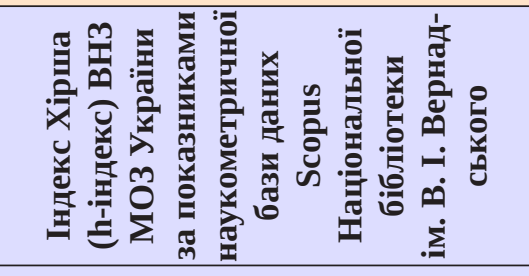 & $\begin{array}{l}\text { ह } \\
\text { Lิ }\end{array}$ & 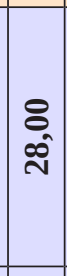 & 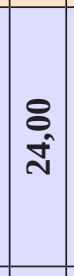 & 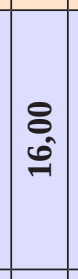 & $\mid \begin{array}{l}8 \\
6 \\
-0\end{array}$ & $\begin{array}{l}\text { E } \\
\mathfrak{y}\end{array}$ & $\begin{array}{l}\theta_{0} \\
\hat{\theta}\end{array}$ & $\begin{array}{l}8 \\
\sigma^{\prime}\end{array}$ & $\begin{array}{l}8 \\
\sigma^{2}\end{array}$ & $\begin{array}{l}8 \\
\infty \\
\infty\end{array}$ & $\begin{array}{l}8 \\
\infty\end{array}$ & ह & $\begin{array}{l}8 \\
0 \\
0\end{array}$ & $\begin{array}{l}8 \\
15 \\
10\end{array}$ & $\begin{array}{l}8 \\
\text { in }\end{array}$ & $\begin{array}{l}8 \\
10^{\circ}\end{array}$ & $\begin{array}{l}\delta \\
\text { N }\end{array}$ \\
\hline$\stackrel{M}{\underline{m}}$ & $\sum^{\lambda}$ & $\sum^{\lambda}$ & $\sum_{i}^{\lambda}$ & 㤩 & $\sum_{\bar{X}}^{\lambda}$ & $\sum_{0}^{\lambda}$ & $\mid \begin{array}{l}\hat{\theta} \\
\text { 离 }\end{array}$ & $\sum_{\text {点 }}^{\lambda}$ & $\sum_{i}^{\vec{\theta}}$ & 蓄 & 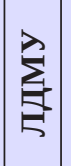 & $\sum_{\text {空 }}^{\lambda}$ & $\sum_{\substack{x \\
\sum_{x}}}^{\circ}$ & 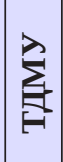 & $\sum_{i=\mid}^{\lambda}$ & $\sum_{\lambda}^{\overleftarrow{S}}$ & $\sum_{\text {住 }}^{O}$ \\
\hline 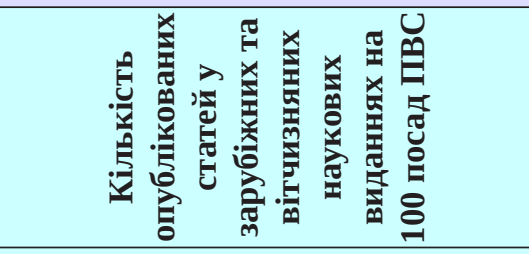 & $\begin{array}{l}\hat{乏} \\
\hat{=}\end{array}$ & $\begin{array}{l}R \\
\text { L }\end{array}$ & $\begin{array}{l}\stackrel{\infty}{\hat{T}} \\
\stackrel{\infty}{\infty}\end{array}$ & $\left|\begin{array}{l}\mathscr{1} \\
\hat{\infty} \\
\infty\end{array}\right|$ & $\mid \begin{array}{l}1 \\
0 \\
8 \\
8 \\
\infty\end{array}$ & $\begin{array}{l}8 \\
\infty \\
\infty \\
10\end{array}$ & $\mid \begin{array}{l}\mathscr{0} \\
\hat{\sigma} \\
0\end{array}$ & $\begin{array}{l}\tilde{W} \\
\sigma^{2}\end{array}$ & $\begin{array}{l}2 \\
\vec{j} \\
\overrightarrow{7}\end{array}$ & $\frac{\hat{n}}{\hat{m}}$ & $\begin{array}{l}\bar{\Xi} \\
\hat{N}\end{array}$ & 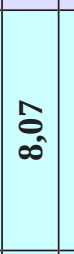 & ले & 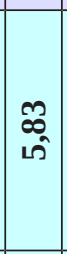 & $\begin{array}{l}\hat{\theta} \\
\text { in }\end{array}$ & 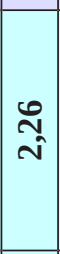 & ¿ \\
\hline$\stackrel{m}{M}$ & 运 & 突 & $\sum_{\text {m }}^{\lambda}$ & 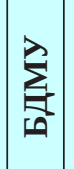 & 公 & 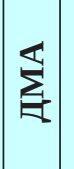 & 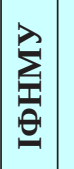 & 离 & $\sum_{\substack{S \\
\sum}}$ & $\sum_{i=}^{\lambda}$ & $\sum_{M}^{\lambda}$ & 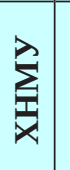 & 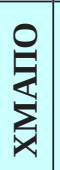 & 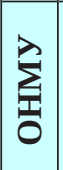 & 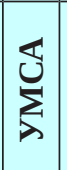 & 齐 & $\sum_{-2}^{\lambda}$ \\
\hline 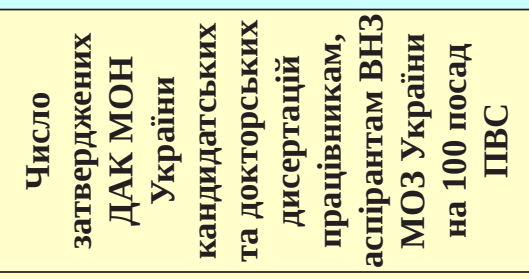 & $\bar{\infty}$ & $\stackrel{J}{\stackrel{J}{n}}$ & $\left|\begin{array}{l}\infty \\
\infty \\
\omega^{n}\end{array}\right|$ & $\begin{array}{l}\mathcal{Z} \\
\text { in }\end{array}$ & 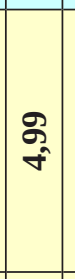 & 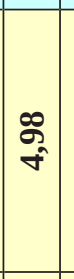 & $\begin{array}{c}n \\
\stackrel{2}{f}\end{array}$ & $\begin{array}{l}n \\
\tilde{f}\end{array}$ & $\begin{array}{c}\vec{k} \\
\hat{n}\end{array}$ & 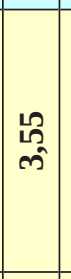 & $\begin{array}{c}\tilde{n} \\
\tilde{n}^{2}\end{array}$ & $\stackrel{f}{\hat{m}}$ & $\frac{m}{\hat{n}}$ & 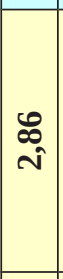 & $\begin{array}{c}\tilde{N} \\
\hat{N}\end{array}$ & 독 & ठ \\
\hline$\stackrel{m}{M}$ & $\sum_{0}^{\lambda}$ & $\sum_{\text {足 }}^{\stackrel{0}{S}}$ & 总 & 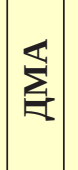 & 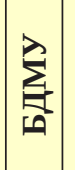 & $\begin{array}{l}\sum_{1}^{\lambda} \\
\underline{\theta} \\
\underline{\theta}\end{array}$ & $\frac{\lambda}{\hat{\theta}}$ & $\frac{\lambda}{m}$ & $\sum_{\mid}^{\lambda}$ & 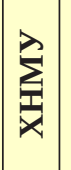 & 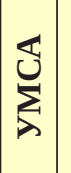 & 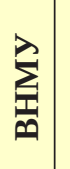 & 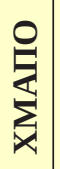 & $\sum_{i}^{\lambda}$ & 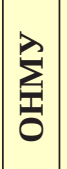 & 兽 & $\sum_{\bar{E}}^{\lambda}$ \\
\hline 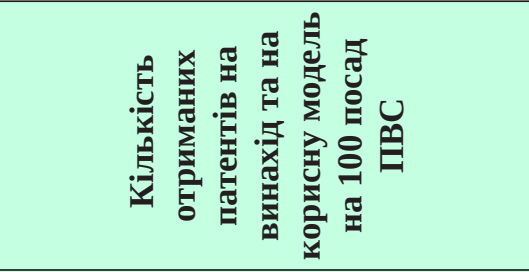 & 志 & $\stackrel{\tilde{q}}{\tilde{m}}$ & $\begin{array}{l}\boldsymbol{g} \\
\hat{\sigma} \\
0\end{array}$ & $\mid \begin{array}{l}\tilde{z} \\
\tilde{0} \\
\tilde{0}\end{array}$ & $\begin{array}{l}\infty \\
\infty \\
\sigma\end{array}$ & $\begin{array}{l}0 \\
\tilde{\omega} \\
\sigma^{2}\end{array}$ & $\begin{array}{c}m \\
\omega \\
\sigma\end{array}$ & $\begin{array}{l}\approx \\
\sigma\end{array}$ & $\begin{array}{c}9 \\
0 \\
0\end{array}$ & 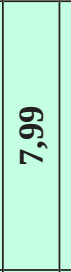 & $\begin{array}{l}2 \\
2 \\
n\end{array}$ & $\underset{g}{g}$ & $\begin{array}{l}\text { है } \\
\text { చै }\end{array}$ & 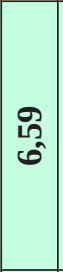 & 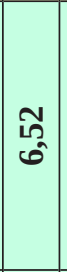 & $\begin{array}{l}12 \\
\stackrel{+}{*}\end{array}$ & : \\
\hline$\underline{M}$ & $\sum_{i}^{\lambda}$ & $\sum_{i=1}^{\lambda}$ & $\sum_{\text {m }}^{O}$ & $\sum_{\substack{|c\\
|}}^{\lambda}$ & $\sum_{i}^{\lambda}$ & 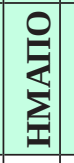 & $\sum$ & $\sum_{\substack{\lambda \\
0}}^{\lambda}$ & 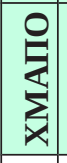 & $\underset{\mathrm{m}}{\stackrel{\lambda}{\mathrm{m}}}$ & $\sum_{\lambda}^{\overleftarrow{\lambda}}$ & $\sum_{\lambda}^{\lambda}$ & $\begin{array}{l}\sum_{i}^{\lambda} \\
\stackrel{\theta}{\theta} \\
\end{array}$ & 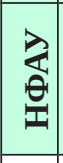 & $\sum^{\lambda}$ & 悬 & $\sum_{-}^{\lambda}$ \\
\hline of & -1 & $N$ & $m$ & $\nabla$ & in & 0 & $\wedge$ & $\infty$ & $\theta$ & 인 & $\Rightarrow$ & $\approx$ & 9 & $\Xi$ & 는 & 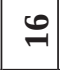 & \\
\hline
\end{tabular}




\begin{tabular}{|c|c|c|c|c|c|c|c|c|c|c|c|c|c|c|c|c|c|}
\hline 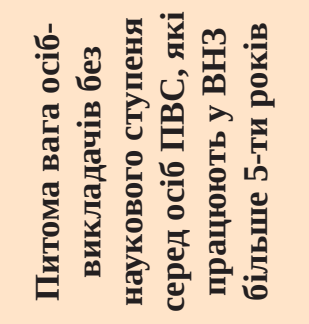 & $\tilde{\theta}_{0}$ & $\begin{array}{l}\tilde{\theta} \\
\hat{\theta}\end{array}$ & $\begin{array}{l}\tilde{\sigma} \\
\tilde{O}^{\prime}\end{array}$ & $\begin{array}{l}\tilde{0} \\
\tilde{0}\end{array}$ & $\begin{array}{l}\tilde{0} \\
\hat{\sigma}\end{array}$ & $\begin{array}{l}20 \\
0^{\circ}\end{array}$ & $\begin{array}{l}\text { LO } \\
0 \\
0\end{array}$ & $\begin{array}{l}12 \\
0 \\
0\end{array}$ & $\begin{array}{l}\mathscr{8} \\
0\end{array}$ & $\hat{\theta}_{0}$ & $\begin{array}{l}\infty \\
0 \\
0 \\
0\end{array}$ & $\frac{9}{9}$ & $\begin{array}{l}Z \\
0 \\
0\end{array}$ & $\frac{7}{0}$ & $\stackrel{\pi}{\Delta}$ & $\begin{array}{l}0 \\
\stackrel{1}{0}\end{array}$ & $\stackrel{1}{0}$ \\
\hline$\stackrel{M}{M}$ & $\sum^{\lambda}$ & $\sum_{\hat{E}}^{\lambda}$ & 怘 & 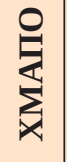 & $\sum^{\lambda}$ & $\frac{\lambda}{\hat{\theta}}$ & 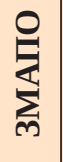 & 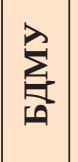 & $\sum_{\text {ले }}^{\stackrel{\lambda}{E}}$ & $\sum_{0}^{\lambda}$ & $\sum_{\lambda}^{\mathbb{J}}$ & $\sum_{\bar{x}}^{\lambda}$ & $\sum_{i}^{\mathbb{E}}$ & $\sum_{\text {畕 }}^{\lambda}$ & $\sum_{i}^{\lambda}$ & $\sum_{\frac{1}{\theta}}^{\lambda}$ & $\sum_{i}^{\lambda}$ \\
\hline 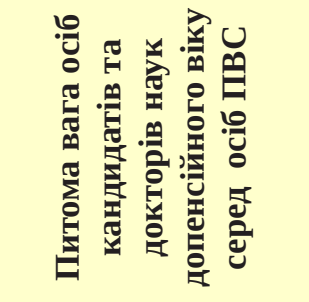 & $\stackrel{n}{\hat{\sigma}}$ & 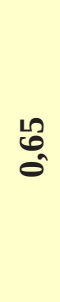 & : & 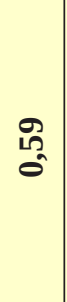 & 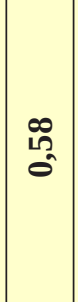 & $\begin{array}{l}L_{0}^{2} \\
0^{2}\end{array}$ & กิ้ & ถุ & $\stackrel{\infty}{\stackrel{\infty}{\circ}}$ & fo & $\begin{array}{c}\hat{f} \\
\sigma_{0}^{\prime}\end{array}$ & f̀ & $\stackrel{0}{\mathscr{f}}$ & $\stackrel{\mathbb{Z}}{\stackrel{J}{0}}$ & $\stackrel{n}{\tilde{q}}$ & $\begin{array}{c}\mathscr{m} \\
\text { के } \\
0\end{array}$ & $\begin{array}{c}\tilde{m} \\
0^{2}\end{array}$ \\
\hline$\stackrel{M}{M}$ & $\sum_{i=1}^{\lambda}$ & $\stackrel{\hat{\theta}}{\hat{\theta}}$ & $\sum_{m}^{0}$ & 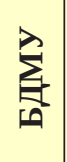 & $\sum_{\lambda}^{\mathbb{J}}$ & 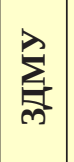 & 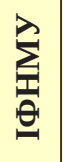 & 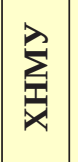 & 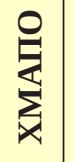 & $\sum^{\stackrel{\lambda}{B}}$ & $\underset{\sum_{1}}{\sum_{1}}$ & $\sum_{\mid \lambda}^{\lambda}$ & 总 & $\sum_{i}^{\lambda}$ & $\sum_{i}^{\mathbb{Z}}$ & $\sum_{\frac{1}{0}}^{\lambda}$ & $\stackrel{\lambda}{\sum^{\lambda}}$ \\
\hline 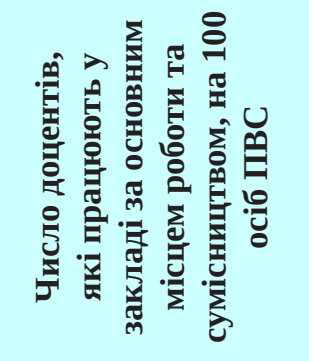 & $\begin{array}{l}\text { E. } \\
\text { हิ }\end{array}$ & $\begin{array}{l}\mathscr{0} \\
\text { If }\end{array}$ & $\begin{array}{l}\tilde{a} \\
\tilde{y}\end{array}$ & $\begin{array}{l}\overline{\sigma_{2}} \\
\hat{m}\end{array}$ & $\begin{array}{l}\hat{N} \\
\text { ven }\end{array}$ & $\begin{array}{l}\stackrel{\infty}{\sim} \\
\stackrel{\tilde{m}}{n}\end{array}$ & $\begin{array}{l}\vec{N} \\
\hat{\tilde{N}}\end{array}$ & $\begin{array}{l}\text { స్ } \\
\text { लె }\end{array}$ & $\begin{array}{l}\text { N̂ } \\
\text { సే }\end{array}$ & $\begin{array}{l}\stackrel{\infty}{0} \\
\text { 今े }\end{array}$ & $\begin{array}{l}m \\
\hat{\sigma} \\
\text { ஸे }\end{array}$ & $\begin{array}{l}\stackrel{2}{\wedge} \\
\hat{N}\end{array}$ & $\begin{array}{l}\infty \\
\infty \\
\text { ڤ్ }\end{array}$ & مी & $\begin{array}{l}\hat{o} \\
\hat{\text { tิ }}\end{array}$ & $\begin{array}{l}\overrightarrow{\tilde{\theta}} \\
\hat{\tilde{v}}\end{array}$ & 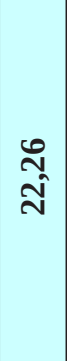 \\
\hline$\stackrel{M}{M}$ & $\frac{\hat{\theta}}{\hat{\theta}}$ & $\sum_{i=1}^{\lambda}$ & $\sum_{\substack{2 \\
\sum_{x}}}^{0}$ & $\sum_{m}^{\circ}$ & 寔 & 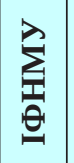 & $\sum_{\underbrace{}_{10}}^{\lambda}$ & 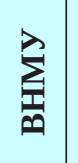 & $\sum_{j}^{J}$ & 至 & 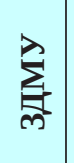 & $\sum_{\substack{x \\
x}}^{\lambda}$ & $\sum_{0}^{\lambda}$ & 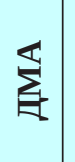 & $\sum_{\mid}^{\lambda}$ & $\underset{⿱ 乛}{\stackrel{\lambda}{S}}$ & 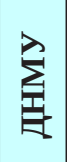 \\
\hline 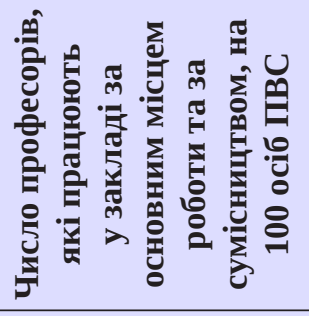 & $\stackrel{\text { Iִ }}{\text { ลิ }}$ & $\begin{array}{l}\infty \\
0 \\
\stackrel{0}{0} \\
\infty \\
-1\end{array}$ & $\begin{array}{l}20 \\
0 \\
-1\end{array}$ & $\begin{array}{c}\tilde{O} \\
\hat{\omega}\end{array}$ & $\begin{array}{l}\text { Dे } \\
\text { เి }\end{array}$ & $\begin{array}{l}m \\
m \\
\tilde{I}\end{array}$ & $\begin{array}{l}\tilde{\sigma} \\
\hat{n}\end{array}$ & 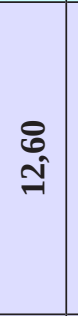 & $\begin{array}{l}\text { ले } \\
\text { సี }\end{array}$ & $\stackrel{\tilde{y}}{=}$ & $\begin{array}{l}0 \\
= \\
=\end{array}$ & $\stackrel{0}{=}$ & $\begin{array}{l}\hat{1} \\
\hat{0} \\
\hat{-}\end{array}$ & $\begin{array}{l}\hat{\infty} \\
\sigma^{\infty}\end{array}$ & $\stackrel{n}{\mathscr{n}}$ & $\begin{array}{l}\text { लै } \\
\sigma^{2}\end{array}$ & $\begin{array}{l}\overrightarrow{0} \\
\infty\end{array}$ \\
\hline$\stackrel{m}{M}$ & 是 & 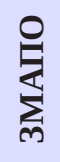 & 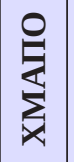 & $\sum_{\mid \lambda}^{\lambda}$ & 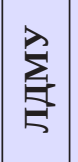 & $\begin{array}{l}\hat{\theta} \\
\hat{\theta}\end{array}$ & $\sum_{\mathrm{E}}^{\mathrm{B}}$ & $\sum_{\lambda}^{\mathbb{S}}$ & 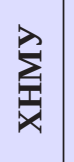 & $\sum^{\mathbb{E}}$ & 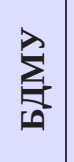 & $\sum_{\text {ल }}^{\lambda}$ & $\sum^{\lambda}$ & $\sum_{0}^{\lambda}$ & $\sum_{\theta}^{\lambda}$ & 兽 & $\sum_{i=0}^{\lambda}$ \\
\hline 인 톴 & $\neg$ & $v$ & $n$ & $\nabla$ & مL & 0 & $\Lambda$ & $\infty$ & $\sigma$ & 우 & $\exists$ & $\approx$ & $\stackrel{n}{\rightarrow}$ & $\Xi$ & $\stackrel{2}{\sim}$ & $\stackrel{\bullet}{-1}$ & -1 \\
\hline
\end{tabular}




\begin{tabular}{|c|c|c|c|c|c|c|c|c|c|c|c|c|c|c|c|}
\hline 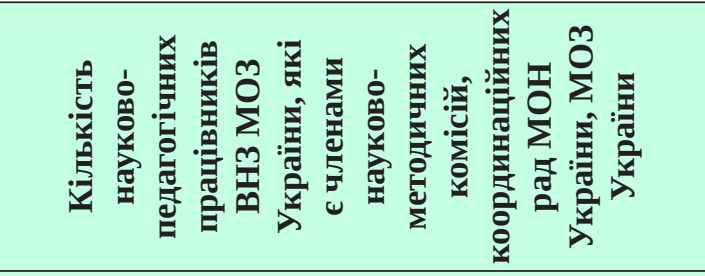 & 농 & 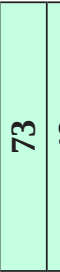 & 电 & 过 & ఖి & เి & $\vec{v}$ & $\approx$ & & $\because \infty$ & $\infty$ & $\wedge$ & 10 & $m$ & -1 \\
\hline$\stackrel{M}{\underline{M}}$ & $\vec{\lambda}$ & $\sum^{\lambda}$ & $\sum_{1}^{0}$ & $\stackrel{\vec{i}}{\vec{E}}$ & & $\sum_{0}^{\lambda}$ & $\frac{\vec{\theta}}{\hat{\theta}}$ & $\sum_{2}^{\mathbb{Z}}$ & & 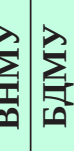 & $\sum_{1}^{\lambda}$ & 足 & 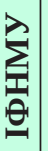 & & \\
\hline 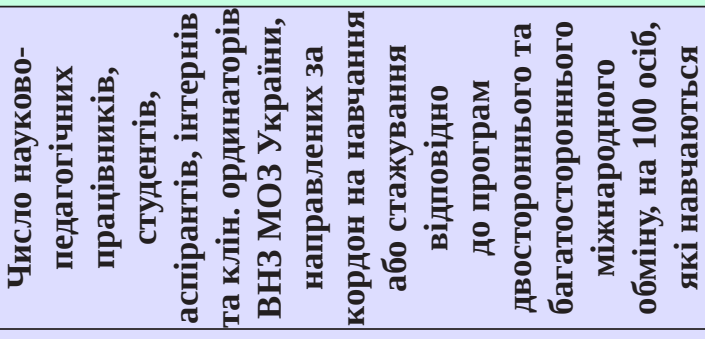 & & & 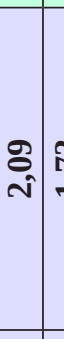 & 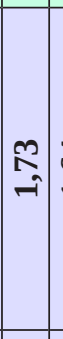 & & 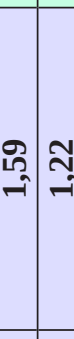 & $\begin{array}{l}y \\
\text { y. }\end{array}$ & $\left|\begin{array}{l}12 \\
\infty \\
0 \\
0\end{array}\right|$ & & $\begin{array}{c}m \\
\overbrace{}^{m}\end{array}$ & $\left|\begin{array}{c}\mathbf{N} \\
0^{2}\end{array}\right|$ & $\begin{array}{c}\frac{12}{2} \\
0^{\prime}\end{array}$ & $\begin{array}{l}8 \\
8 \\
0\end{array}$ & & ठ̊ \\
\hline$\stackrel{M}{=}$ & 齐 & $\sum_{i=}^{\lambda}$ & $\sum_{\substack{x \\
\hdashline}}$ & $\sum^{\$}$ & $\sum_{\infty}^{\lambda}$ & $\sum_{\mid=}^{\lambda} \sum_{\bar{\theta}}^{\lambda}$ & $\vec{\sum}$ & $\sum_{\frac{1}{10}}^{\lambda}$ & & 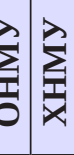 & $\mid \begin{array}{l}\vec{a} \\
\hat{\theta} \\
\hat{\mathbf{v}}\end{array}$ & 说 & $\sum_{\substack{0 \\
\vdots}}^{0}$ & & $\sum_{\bar{\delta}}^{\lambda}$ \\
\hline 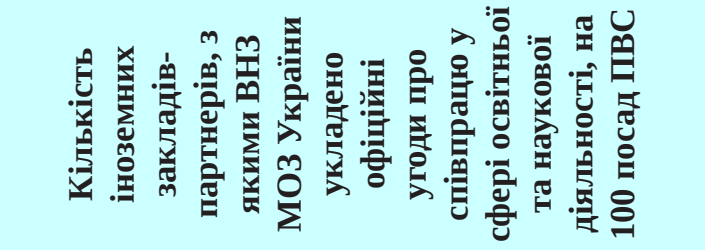 & $\begin{array}{c}\text { నิ } \\
\text { งิ }\end{array}$ & 周 & $\stackrel{2}{=}$ & $\left|\begin{array}{c}\mathscr{2} \\
0 \\
0\end{array}\right|$ & \begin{tabular}{l|l}
$\mathscr{8}$ & \\
0 & \\
0 &
\end{tabular} & $\begin{array}{ll}2 & \text { Ln } \\
0 & 0\end{array}$ & $\begin{array}{l}8 \\
0\end{array}$ & $\mid \begin{array}{c}n \\
1 \\
0 \\
0\end{array}$ & \begin{tabular}{l}
$\infty$ \\
\multirow{a}{*}{} \\
0
\end{tabular} & $\overrightarrow{\sigma^{\prime}} \bar{m}$ & $\frac{\pi}{2}$ & $\begin{array}{l}\mathbf{\delta} \\
\tilde{\theta}^{\prime}\end{array}$ & $\begin{array}{l}8 \\
8 \\
0\end{array}$ & $\begin{array}{l}8 \\
\text { छे }\end{array}$ & $\begin{array}{l}\text { ठ } \\
\text { ठ }\end{array}$ \\
\hline$\stackrel{M}{\pi}$ & 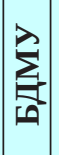 & $\sum_{-1}^{\lambda}$ & 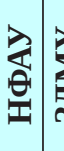 & $\sum_{m}^{\lambda}$ & $\sum_{\vec{x}}^{\lambda}$ & 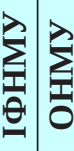 & 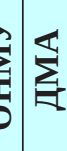 & $\sum^{2}$ & & $\sum_{i} \sum_{\lambda}$ & 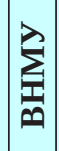 & 说 & $\sum_{\substack{\infty \\
\vdots}}^{0}$ & & $\sum^{\frac{\lambda}{5}}$ \\
\hline 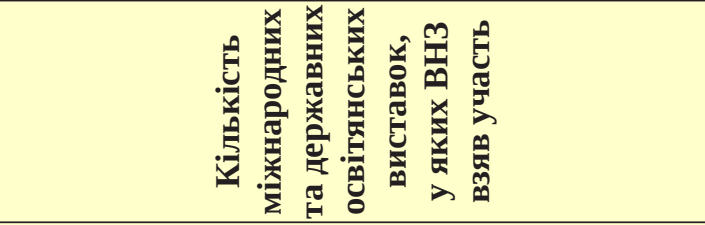 & $\hat{\sigma}$ & ? & ๙ి & เั้ & $=$ & $\sigma \infty$ & 0 & 0 & 0 & ما مـ & $m$ & $\infty$ & -1 & 0 & 0 \\
\hline$\stackrel{M}{M}$ & 齐 & $\sum_{i}^{\lambda}$ & $\sum_{0=1}^{2}$ & 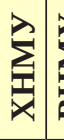 & $\sum_{\substack{n \\
\mid}}^{\lambda}$ & $\sum_{\lambda} \sum_{\lambda} \sum_{m}^{\lambda}$ & 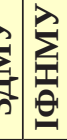 & $\sum$ & $\sum^{3}$ & & 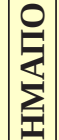 & $\sum_{0}^{\lambda}$ & 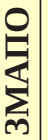 & $\sum_{\underline{1}}^{\lambda}$ & $\sum_{\bar{\delta}}^{\lambda}$ \\
\hline 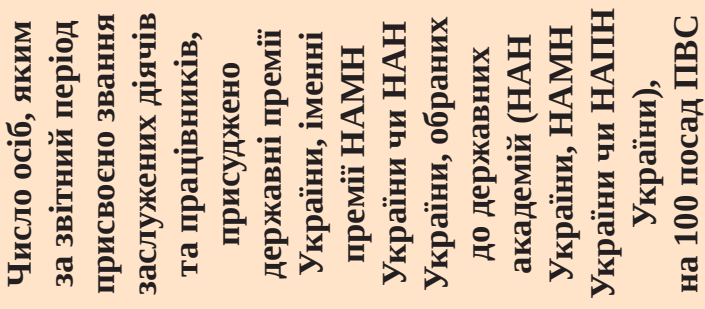 & & & \begin{tabular}{l|l} 
&
\end{tabular} & 10 & $\nabla$ & $m m$ & 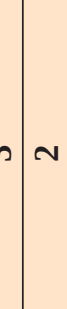 & $N$ & $N o$ & $N-1$ & -1 & -1 & -1 & -1 & 0 \\
\hline 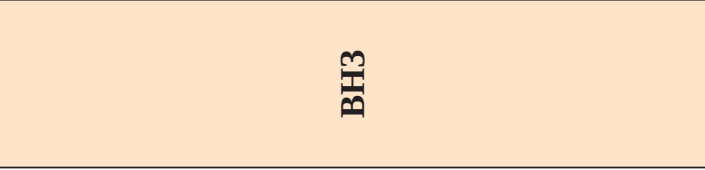 & 说 & $\sum_{i}^{\lambda}$ & $\sum_{\substack{1 \\
\theta}}^{c}$ & $\sum_{0}^{2}$ & $\sum_{0}^{2}$ & $\sum_{i}^{\lambda}$ & 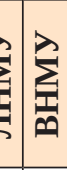 & 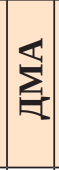 & $\sum_{m}$ & $\sum_{x}^{\lambda}$ & $\sum^{\lambda}$ & $\mid \begin{array}{l}\hat{\hat{\theta}} \\
\frac{\hat{\theta}}{\mathbf{I}} \\
\end{array}$ & 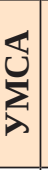 & $\sum_{\substack{\lambda \\
\lambda}}^{\lambda}$ & $\sum_{m}$ \\
\hline 之를 톨 & -1 & N & $m=$ & $\nabla$ & L 10 & $0 \wedge$ & $\infty$ & $\theta$ & ? & $\exists \approx$ & $\approx$ & \pm & -1 & & \\
\hline
\end{tabular}




\begin{tabular}{|c|c|c|c|c|c|c|c|c|c|c|c|c|c|c|c|c|c|}
\hline 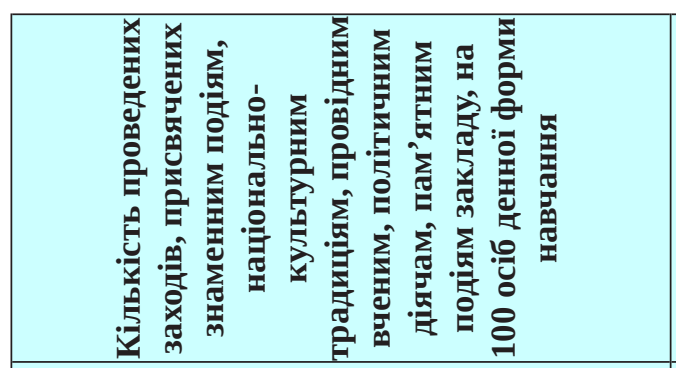 & 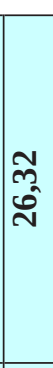 & $\begin{array}{l}\overrightarrow{1} \\
\stackrel{0}{-}\end{array}$ & 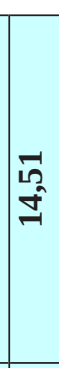 & 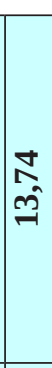 & $\begin{array}{l}m \\
m \\
\infty \\
\infty\end{array}$ & $\left|\begin{array}{c}\text { 认ู้ } \\
\text { เก้ }\end{array}\right|$ & $\begin{array}{l}z \\
\text { so }\end{array}$ & $\mid \begin{array}{c}0 \\
-1 \\
-1\end{array}$ & \begin{tabular}{|}
$\bar{N}$ \\
$\tilde{m}$
\end{tabular} & 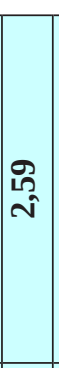 & $\begin{array}{l}\text { స్ } \\
\text { ( }\end{array}$ & $\vec{\lambda}$ & 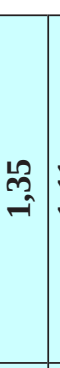 & & $\begin{array}{l}y \\
0\end{array}$ & ले & \\
\hline$\stackrel{M}{M}$ & $\stackrel{\lambda}{i}$ & $\frac{\hat{\theta}}{\hat{\theta}}$ & 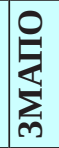 & 齐 & 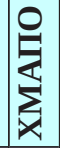 & 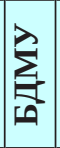 & $\sum_{\text {int }}^{\lambda}$ & 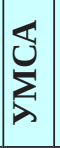 & 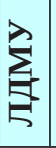 & $\sum_{z}$ & $\sum_{0}^{\lambda}$ & 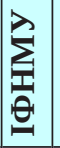 & & & & & \\
\hline 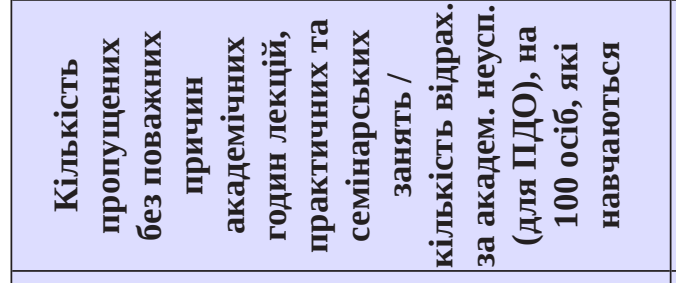 & 8 & लి & ๙ू & 气̂. & $\begin{array}{l}\infty \\
\infty \\
\tilde{m}\end{array}$ & $\begin{array}{l}2 \\
\infty \\
\infty \hat{n}\end{array}$ & 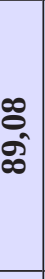 & 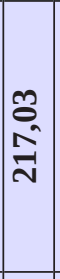 & $\begin{array}{l} \pm \\
\text { בิ } \\
\text { ลี }\end{array}$ & 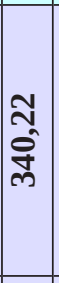 & & 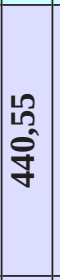 & $\begin{array}{l}\text { है } \\
\text { है }\end{array}$ & & & & \\
\hline$\stackrel{M}{M}$ & 说 & 送 & $\sum_{i=1}^{\lambda}$ & 蒏 & 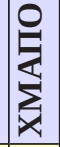 & 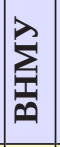 & $\sum_{0}^{\lambda}$ & $\sum_{\bar{m}}$ & $\begin{array}{l}\overrightarrow{\hat{\theta}} \\
\overrightarrow{\mid} \\
\overrightarrow{\mid}\end{array}$ & $\sum^{\lambda}$ & $\sum_{10}^{\lambda}$ & 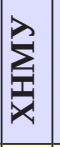 & $\frac{\sum_{i}^{\lambda}}{\underline{\theta}}$ & & & & \\
\hline 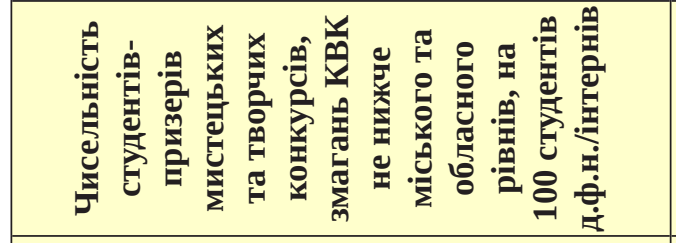 & $\begin{array}{l}\text { ผn } \\
\hat{\text { Oे }}\end{array}$ & $\begin{array}{l}\text { Jू } \\
\sigma\end{array}$ & 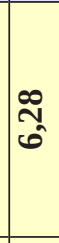 & $\begin{array}{l}\tilde{N} \\
\text { nీ }\end{array}$ & ำ & $\mid \begin{array}{l}\infty \\
\hat{\sim} \\
\hat{v}\end{array}$ & लि & $\widehat{\widehat{N}}$ & $\underset{\sim}{\tilde{\sim}}$ & क्ष & $\begin{array}{c}\infty \\
\infty \\
0 \\
0\end{array}$ & $\overline{0}$ & $\begin{array}{l}\text { Rे } \\
\text { on }\end{array}$ & & 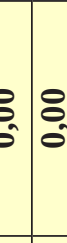 & 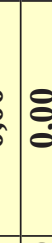 & \\
\hline$\stackrel{m}{\underline{m}}$ & $\sum^{\lambda}$ & 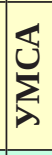 & $\sum^{\lambda}$ & $\sum_{10}^{\lambda}$ & $\sum_{i=1}^{\lambda}$ & $\sum_{i=1}^{\lambda}$ & $\sum_{\bar{x}}^{\lambda}$ & 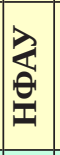 & 至 & $\sum_{\bar{S}}^{\lambda}$ & $\sum_{m}^{\lambda}$ & 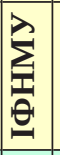 & & & & $\sum_{1}^{2}$ & \\
\hline 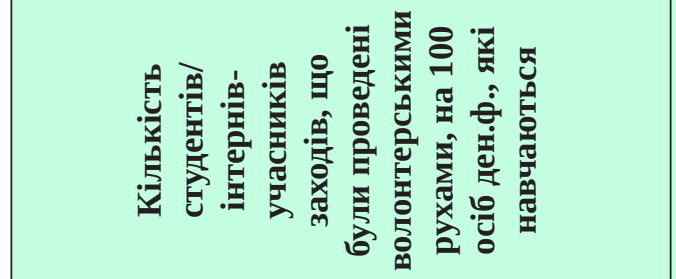 & $\begin{array}{l}\hat{m} \\
\hat{N} \\
\infty \\
\infty \\
\infty\end{array}$ & 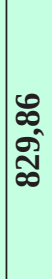 & $\frac{\vec{n}}{\tilde{m}}$ & 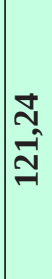 & $\mid \begin{array}{l}\hat{\sigma} \\
\infty \\
\tilde{\sigma}^{\prime}\end{array}$ & $\begin{array}{l}8 \\
0 \\
8\end{array}$ & \begin{tabular}{l}
0 \\
12 \\
\multirow{N}{*}{} \\
$\mathbb{N}$
\end{tabular} & $\begin{array}{l}\hat{\hat{b}} \\
\hat{\tilde{n}}\end{array}$ & $\begin{array}{l}\hat{\Omega} \\
\hat{\kappa} \\
\hat{m}\end{array}$ & 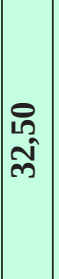 & $\begin{array}{l}\text { के } \\
\text { ผે }\end{array}$ & $\begin{array}{l}\hat{0} \\
\dot{N}\end{array}$ & 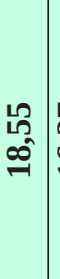 & & & $\ddot{m}_{m}^{\infty}$ & \\
\hline$\stackrel{M}{M}$ & $\sum^{\lambda}$ & $\sum_{\lambda}^{\infty}$ & $\sum_{i=1}^{\lambda}$ & 说 & 主 & 㖣 & 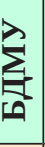 & $\sum^{\nwarrow}$ & 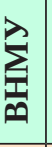 & 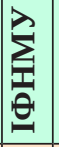 & $\sum_{\mid \lambda}^{\lambda}$ & $\sum_{m}^{\lambda}$ & 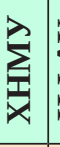 & $\underline{\underline{\theta}}$ & & 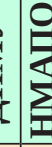 & \\
\hline 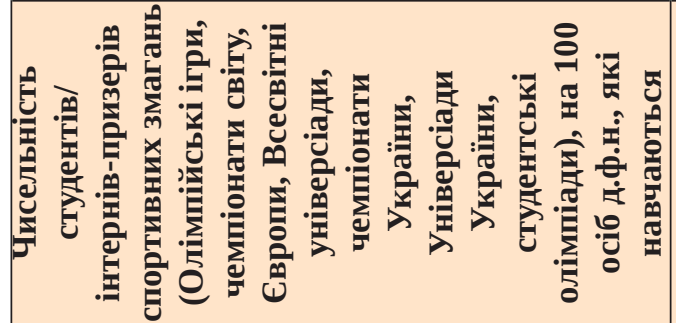 & $\begin{array}{l}\hat{b} \\
f^{\prime}\end{array}$ & $\begin{array}{l}8 \\
\text { i }\end{array}$ & \begin{tabular}{l}
0 \\
\multirow{2}{*}{} \\
-
\end{tabular} & $\stackrel{0}{2}$ & $\stackrel{4}{\stackrel{2}{2}}$ & $\begin{array}{l}\mathscr{\theta} \\
0 \\
0\end{array}$ & $\begin{array}{l}\text { L } \\
0 \\
0\end{array}$ & $\begin{array}{c}\hat{n} \\
\hat{0} \\
0^{\prime}\end{array}$ & $\begin{array}{c}\text { ले } \\
\text { ô }\end{array}$ & $\begin{array}{l}\text { N̂̀ } \\
\text { הू }\end{array}$ & $\begin{array}{l}\bar{N} \\
\text { on }\end{array}$ & $\stackrel{\infty}{0}$ & $\begin{array}{l}0 \\
0 \\
0\end{array}$ & & $=0$ & छ & \\
\hline$\stackrel{m}{M}$ & 囬 & & 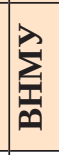 & $\sum_{10}^{\lambda}$ & $\sum_{m}^{\lambda}$ & 俍 & 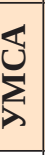 & 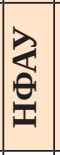 & $\sum_{\substack{x \\
\vdots}}$ & $\sum_{\text {足 }}$ & 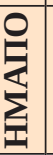 & 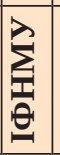 & $\sum_{i=1}^{\lambda}$ & & $\sum_{i}$ & $\sum_{-}^{\lambda}$ & \\
\hline 品 $\frac{F}{m}$ & -1 & N & $n$ & $\nabla$ & L & 0 & $\wedge$ & $\infty$ & $\sigma$ & 으 & $\Rightarrow$ & $\approx$ & 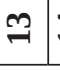 & \pm & $\begin{array}{lll}0 & 0 \\
\end{array}$ & 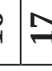 & \\
\hline
\end{tabular}




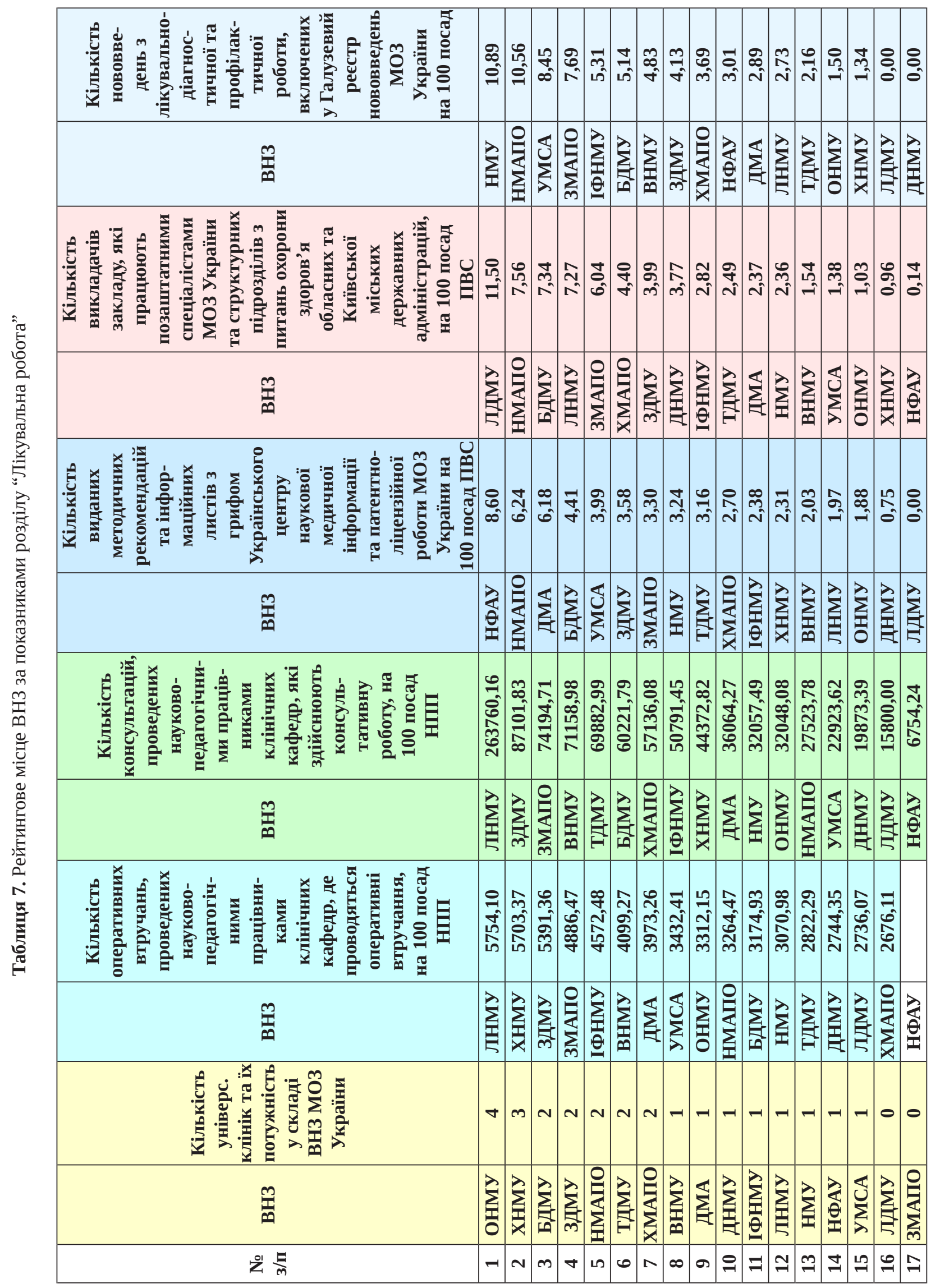




\begin{tabular}{|c|c|c|c|c|c|c|c|c|c|c|c|c|c|c|c|c|}
\hline 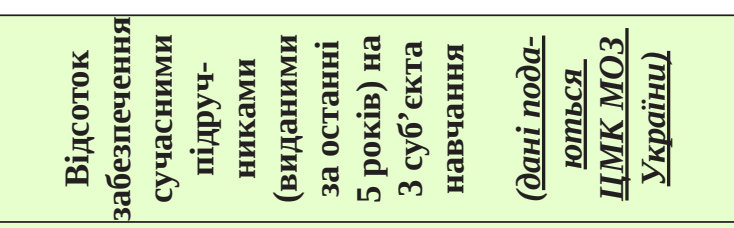 & & & & & $\begin{array}{c}\text { స్ } \\
\hat{\tilde{\vartheta}}\end{array}$ & $\begin{array}{l}8 \\
\hat{\theta}\end{array}$ & & $\begin{array}{l}m \\
m \\
f\end{array}$ & & & $\begin{array}{l}1 \\
L \\
\infty \\
\infty\end{array}$ & $\begin{array}{l}\stackrel{\Xi}{ } \\
\dot{\mathrm{m}}\end{array}$ & & 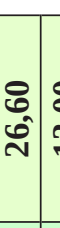 & & $\begin{array}{l}8 \\
0 \\
0\end{array}$ \\
\hline$\stackrel{M}{M}$ & $\sum_{\substack{x \\
\hdashline}}^{0}$ & 呈 & $\sum_{\substack{\infty \\
\sum_{m}}}$ & 竞 & 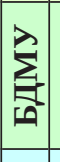 & $\sum^{\lambda}$ & 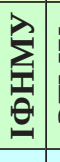 & $\sum_{m}^{\lambda}$ & & & $\sum_{\delta}^{\int}$ & $\sum_{i}^{\Xi}$ & $\begin{array}{l}\hat{\theta} \\
\hat{\mathbf{\theta}}\end{array}$ & 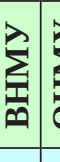 & & 音 \\
\hline 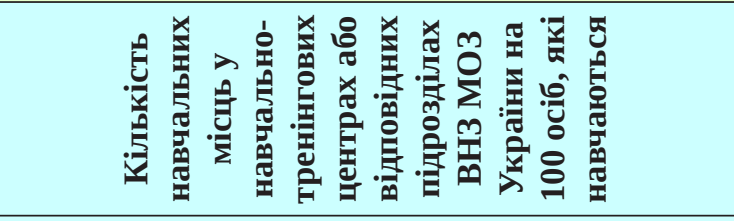 & 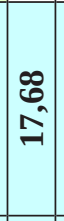 & $\begin{array}{l}12 \\
0 \\
0 \\
=\end{array}$ & 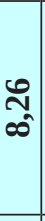 & $\left|\begin{array}{|c}10 \\
0 \\
6\end{array}\right|$ & 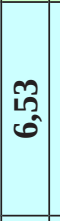 & 의 & $\begin{array}{l}\bar{b} \\
10\end{array}$ & เి & & & $\stackrel{8}{8}$ & 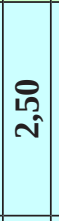 & $\stackrel{\infty}{\sim}$ & ప్ & & $\begin{array}{l}8 \\
0 \\
0\end{array}$ \\
\hline$\stackrel{m}{\mathbf{P}}$ & 空 & 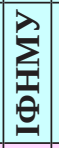 & $\sum_{10}^{\lambda}$ & $\mid \begin{array}{l}\lambda \\
\sum_{0}^{2} \\
\end{array}$ & $\sum^{\lambda}$ & $\sum_{\substack{\sum^{\prime}\\
}}$ & $\sum_{i}$ & $\sum_{1}^{0}$ & & & $\sum_{m}^{\lambda}$ & 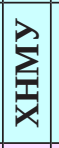 & $\sum_{I}^{\lambda}$ & $\sum_{0}^{2}$ & & $\frac{2}{3}$ \\
\hline 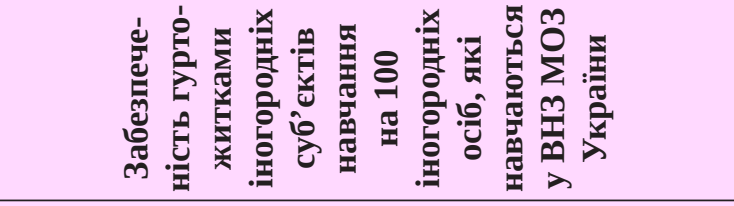 & 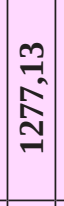 & $\begin{array}{l}\tilde{\infty} \\
1 \\
\hat{m} \\
= \\
=\end{array}$ & 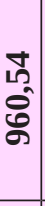 & $\left|\begin{array}{c}\frac{10}{1} \\
10 \\
\sigma \\
\sigma\end{array}\right|$ & 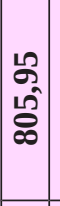 & 望 & & 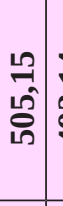 & & & 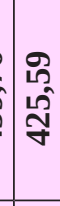 & $\left|\begin{array}{l}\stackrel{2}{0} \\
\hat{\mathbb{m}} \\
\text { m}\end{array}\right|$ & & $\begin{array}{l}\text { న̂ } \\
\text { ถิ }\end{array}$ & & $\begin{array}{l}8 \\
0 \\
0\end{array}$ \\
\hline$\stackrel{M}{M}$ & 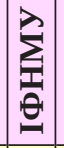 & 暀 & $\sum_{\substack{j \\
\vdots}}$ & 坣 & $\sum_{\substack{\infty\\
}}^{O}$ & 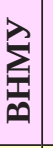 & $\begin{array}{l}\sum_{1}^{\lambda} \\
0\end{array}$ & 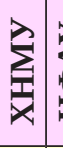 & 商 & & $\sum_{=}^{\lambda}$ & 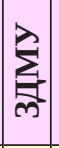 & $\sum_{10}^{\lambda}$ & $\sum_{i}^{\lambda}$ & & $\frac{2}{3}$ \\
\hline 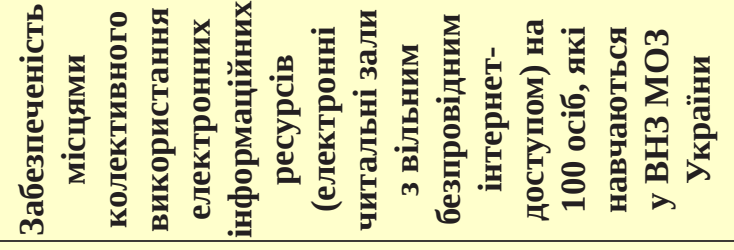 & $\underset{0}{20}$ & $\begin{array}{l}\tilde{\theta} \\
- \\
-\end{array}$ & นี & $\stackrel{g}{g}$ & $\mid$ & $\begin{array}{l}2 \\
0 \\
0\end{array}$ & $\begin{array}{l}\tilde{6} \\
0 \\
0\end{array}$ & 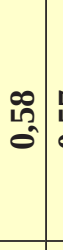 & \begin{tabular}{l|l}
$\hat{n}$ \\
$\hat{0}$ \\
0
\end{tabular} & & लि & $\frac{9}{0}$ & ह & $\hat{\theta}$ & & $\begin{array}{l}0 \\
0 \\
0\end{array}$ \\
\hline$\stackrel{M}{M}$ & 葛 & 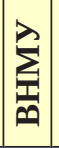 & 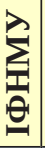 & 盝 & $\sum^{\lambda}$ & 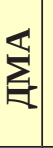 & $\sum_{\substack{x \\
:}}^{O}$ & $\sum_{-1}^{\lambda}$ & $\sum_{10}^{\lambda}$ & & $\sum_{\lambda}^{\mathbb{S}}$ & $\sum^{\lambda}$ & $\sum_{0}^{\pi}$ & $\sum_{\bar{x}}^{\lambda}$ & & $\frac{\sum}{3}$ \\
\hline 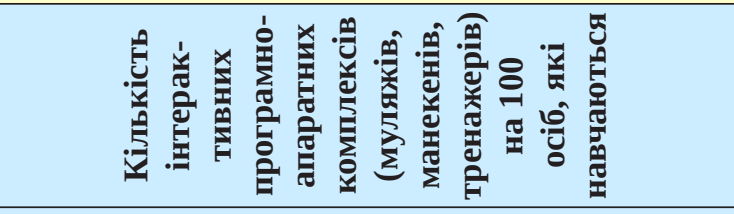 & $\begin{array}{c}0 \\
\text { in } \\
\text { in }\end{array}$ & $\begin{array}{c}\stackrel{m}{\mathrm{~m}} \\
\vec{\nabla}\end{array}$ & הa & $\begin{array}{c}\tilde{n} \\
\tilde{\sigma} \\
0\end{array}$ & $\begin{array}{l}0 \\
2 \\
0\end{array} \mid$ & $\begin{array}{l}n \\
\hat{0} \\
0\end{array}$ & $\begin{array}{l}\infty \\
0 \\
0 \\
0\end{array}$ & $\begin{array}{l}\infty \\
+ \\
0 \\
0\end{array}$ & ब̂ & $=$ & O & $\begin{array}{l}\infty \\
0 \\
0 \\
0\end{array}$ & है & $\begin{array}{l}8 \\
0\end{array}$ & & $\begin{array}{l}8 \\
0 \\
0\end{array}$ \\
\hline$\stackrel{M}{\underline{m}}$ & 窟 & 恿 & $\sum_{\substack{\lambda \\
\lambda}}^{\lambda}$ & 盝 & 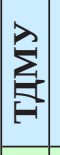 & 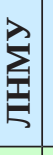 & & 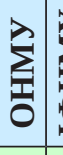 & $\begin{array}{l}\sum_{1}^{\lambda} \\
\theta \\
\theta\end{array}$ & 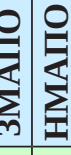 & $\sum_{10}^{\lambda}$ & 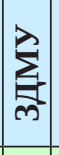 & 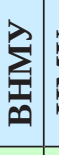 & $\sum_{i}^{\lambda}$ & & 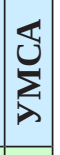 \\
\hline 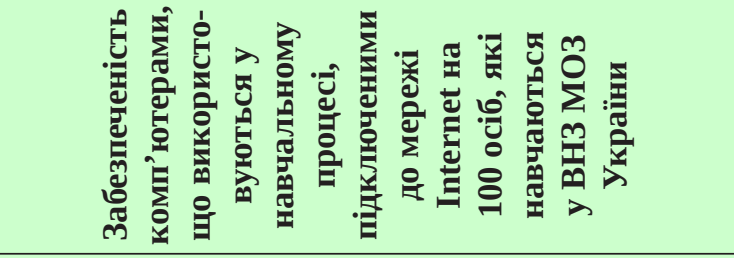 & $\begin{array}{l}\stackrel{L}{N} \\
\stackrel{\text { Na }}{\text { an }}\end{array}$ & $\begin{array}{l}\tilde{N} \\
\hat{\sigma}^{2}\end{array}$ & $\begin{array}{l}0 \\
\mathbf{b} \\
10 \\
-1\end{array}$ & $\begin{array}{c}2 \\
\tilde{m} \\
\vec{q}\end{array} \mid$ & $\begin{array}{l}\vec{\Delta} \\
\text { ma }\end{array}$ & 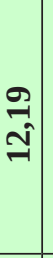 & $\begin{array}{l}0 \\
f \\
= \\
=\end{array}$ & $\begin{array}{l}\infty \\
\stackrel{0}{=} \\
=\end{array}$ & & & $\begin{array}{l}2 \\
0 \\
\infty\end{array}$ & $\begin{array}{c}\bar{m} \\
\infty \\
\infty\end{array}$ & مे & 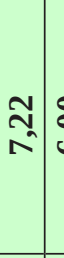 & & $\begin{array}{c}\hat{0} \\
\text { மी } \\
\text { in }\end{array}$ \\
\hline$\stackrel{M}{M}$ & $\sum_{\substack{x \\
\sum_{x}}}$ & 良 & 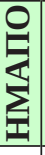 & 育 & 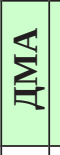 & 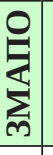 & $\sum_{i}^{\lambda}$ & $\sum_{\substack{\Delta \\
\mid}}^{\lambda}$ & $\sum_{10}^{\lambda}$ & $\vec{v}$ & $\sum^{\lambda}$ & 产 & $\frac{\hat{\theta}}{\hat{\theta}}$ & $\sum_{\lambda}^{\mathbb{S}}$ & & $\frac{\sum}{3}$ \\
\hline 乫 $\frac{\mathrm{E}}{\mathrm{m}}$ & -1 & $N$ & $m$ & $\nabla$ & \begin{tabular}{|l|l|} 
& \\
\end{tabular} & 0 & $\triangle$ & $\infty$ & $\sigma \mid$ & $=$ & $\cong$ & 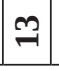 & \pm & $\stackrel{10}{\circ}$ & $\stackrel{0}{-1}$ & 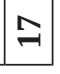 \\
\hline
\end{tabular}




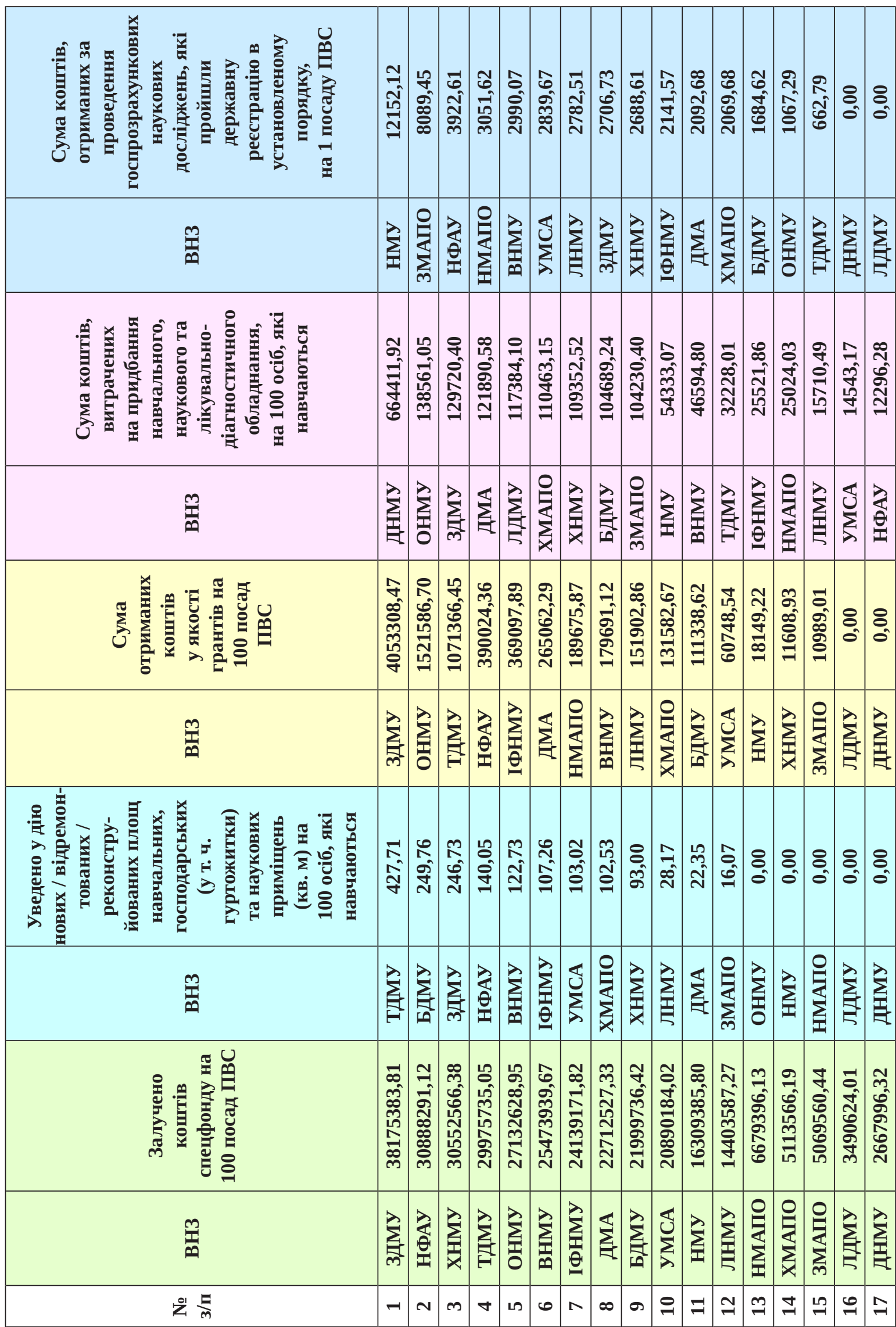


3 розділу “Матеріально-технічне забезпечення":

- збільшення показника забезпеченості комп’ютерами у ЛДМУ, ХНМУ;

- збільшення показника забезпеченості місцями колективного використання електронних інформаційних ресурсів у ДНМУ, ЛДМУ, ОНМУ та ХНМУ;

- збільшення показника забезпеченості сучасними підручниками в ОНМУ.

Висновки: 1. У 2015 р. було уточнено та скориговано показники галузевого рейтингу діяльності

\section{Список літератури}

1. Кайдалова А. В. Актуальні проблеми удосконалення системи оцінки якості вищої фармацевтичної освіти на національному рівні / А. В. Кайдалова, О.В.Посилкіна, О. В. Доровський // Управління, економіка та забезпечення якості в фармації. - 2015. - № 6 (44). - С. 56-62.
ВНЗ МОЗ України за основними напрямками діяльності, їх було затверджено та введено в дію листом МО3 України від 14.01.2016 р. № 08.01-47/647.

2. Аналіз показників показав існування єдиних підходів до організації навчально-методичної роботи щодо підготовки фахівців для галузі охорони здоров’я, що здійснюється МОЗ України.

3. Галузевий моніторинг дозволив визначити сильні та слабкі сторони діяльності кожного ВНЗ, що дає можливість скоригувати перспективний план розвитку навчального закладу для забезпечення належної якості підготовки фахівців.

2. Про вищу освіту : Закон України від 01.07.2014 р. № 1556-VII.

3. Рейтинг ВНЗ МОЗ України [Електронний ресурс]. - Режим доступу : http://www.moz. gov.ua. 